\title{
SHORT-TERM VARIATIONS IN VELOCITY OF SOUTH CASCADE GLACIER, WASHINGTON, U.S.A.
}

\author{
By RoBert W. JACOBEL \\ (Saint Olaf College, Northfield, Minnesota 55057, U.S.A.)
}

\begin{abstract}
Displacement of an array of eight stakes was measured at approximately $12 \mathrm{~h}$ intervals on South Cascade Glacier, Washington, for a period of $638 \mathrm{~h}$ during July and August 1979. The array was located on the glacier center-line and had overall dimensions comparable to the $200 \mathrm{~m}$ ice thickness in this part of the glacier. Variations in velocity for individual stakes was typically $100 \%$ for periods of $12 \mathrm{~h}$ but decreased for longer time intervals in accordance with reports in the literature. The constraint of requiring compatible motion for the entire array reduces the averaged short-term fluctuations to the same order as the variations between stakes for a given $12 \mathrm{~h}$ period. This implies that non-uniformity in individual stake motion does not represent true velocity variation of the studied portion of the glacier.
\end{abstract}

RÉSumé. Variations à courtes périodes de la vitesse du South Cascade Glacier, Washington, U.S.A. Le déplacement d'un ensemble de huit balises a été mesuré à des intervalles d'environ $12 \mathrm{~h}$ sur le South Cascade Glacier pendant une période de $638 \mathrm{~h}$ au cours des mois de juillet et août 1979. Le système de balise était situé sur la ligne centrale du glacier et avait une dimension totale comparable aux deux cents mètres de l'épaisseur de glace dans cette partie du glacier. Les variations individuelles de vitesse des balises étaient de l'ordre de $100 \%$ pour des périodes de $12 \mathrm{~h}$ mais diminuaient pour des intervalles de temps plus longs conformément à ce qui est rapportė dans la littérature. La nécessité de rendre compatibles les mouvements de l'ensemble des balises réduit les fluctuations moyennes à court terme à un ordre de grandeur équivalent à celui des variations entre les balises pour une période de $12 \mathrm{~h}$ donnée. Ceci implique que l'hétérogénéité dans les mouvements individuels des balises ne représente pas la véritable variation de la vitesse de la portion étudiée du glacier.

Zusammenfassung. Kurzzeit-Geschwindigkeiten am South Cascade Glacier, Washington, U.S.A., und ihre Schwankungen. In Intervallen von etwa 12 Stunden wurde während einer Periode von 638 Studen im Juli und August 1979 die Verlagerung einer Anordnung von acht Pegeln auf dem South Cascade Glacier, gemessen. Das Pegelsystem lag auf der Mittellinie des Gletschers; seine Dimensionen waren der Eisdicke von etwa $200 \mathrm{~m}$ in diesem Teil des Gletschers angepasst. Einzelne Pegel wiesen typische Geschwindigkeitsschwankungen von $100 \%$ für Perioden von 12 Stunden auf, die jedoch über längere Zeitintervalle abklangen, ganz in Übereinstimmung mit Berichten aus der Literatur. Die notwendige Einschränkung auf verträgliche Bewegungen für den ganzen Bereich verringert die mittleren kurzfristigen Schwankungen auf dieselbe Grössenordnung wie die der Schwankungen zwischen Pegeln in einer bestimmten 12-Stunden-Periode. Daraus folgt, dass Ungleichförmigkeit der Bewegung einzelner Pegel kein Anzeichen für wirkliche Geschwindigkeitsschwankungen des untersuchten Gletschergebietes ist.

SHORT-TERM variations in glacier velocity have been studied by Meier (1960) on Saskatchewan Glacier, and by Harrison and Lee (1971) on Coleman Glacier on Mount Baker. The situation has been summarized by Paterson (1969) who reports that velocity variations appear to increase as the time over which positions are surveyed decreases. These variations are not correlated with meteorological variables, nor do they show diurnal fluctuations. Nevertheless they are thought to be real effects and not an artifact of the resolution of the measurements.

It is well known that the motion of temperate ice arises from two components: basal sliding and an internal plastic deformation. It has been generally understood that these two components contribute in roughly equal amounts to glacier flow. However, recent bore-hole photography results by Engelhardt and others (1978) from Blue Glacier, Washington, indicate that as little 
as $7 \%$ of the surface motion may be due to basal sliding. If confirmed, these results would seem to place upper limits on the irregularity of motion which can be experienced on the surface.

The present experiment utilizes an eight element array of reflectors positioned along the center line near equilibrium on South Cascade Glacier (see Figure 1). The position of elements in this array was surveyed approximately twice daily using a theodolite and a laser ranger, a distance-measuring device. The overall dimensions of the array are comparable to the $200 \mathrm{~m}$ ice thickness in this area. The motivation for using an array of this size is that compatible motion should be expected for all of the elements, and spurious instrumental effects should show up as fluctuations which are not in phase. The data were taken over $638 \mathrm{~h}$ during July and

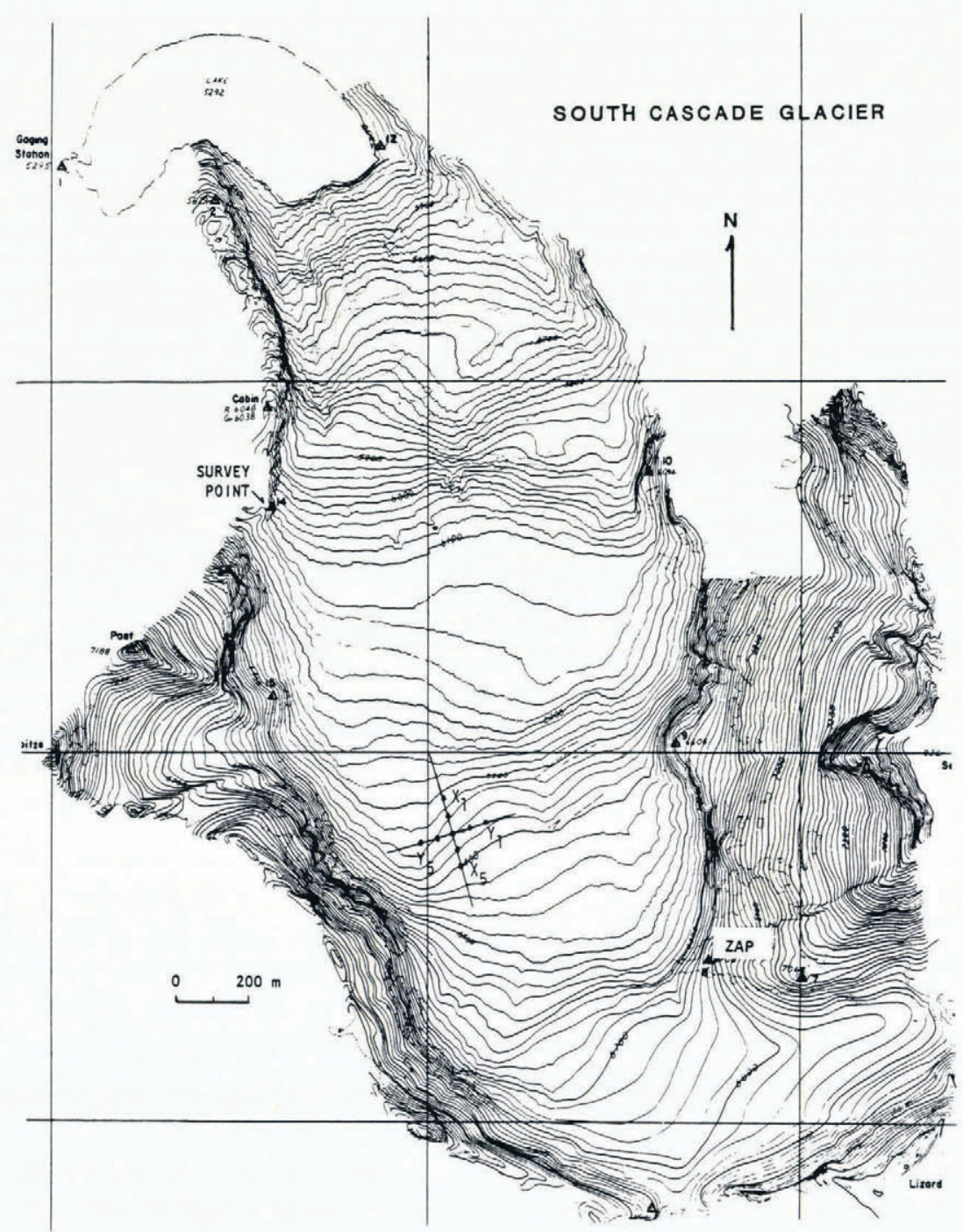

Fig. 1 . 
August 1979. For each $12 \mathrm{~h}$ reading a measurement was made of a fixed survey point (ZAP) and all data were normalized to a constant reference value for its location, thereby minimizing atmospheric effects. The position of a ninth stake $y_{4}$ was measured only at the beginning and the end of the period.

The array distance was $1 \mathrm{~km}$ from the survey location, and the fixed reference point, ZAP, was at $1.6 \mathrm{~km}$. Line-of-sight position was determined for each stake by laser ranger with an instrumental uncertainty of $\pm 5 \mathrm{~mm}$. Typically the variation (standard deviation) for the ten laser-ranger measurements taken for each stake at each observation period was very close to this value. Displacements for each stake are therefore determined to a resolution of $\pm 7 \mathrm{~mm}$. Since the line-of-sight displacement vector is within $12^{\circ}$ of the actual surface velocity vector, it equals about $98 \%$ of the actual motion. Thus the theodolite measurements were not used in this analysis, and all displacements and velocities reported here are line-of-sight components determined by the laser ranger.

The plot of displacement versus time for the eight stakes is shown in Figure 2. The data represent typically $12 \mathrm{~h}$ surveys; gaps are due to periods of fog. A linear least-squares fit was made to the data for each stake individually and the results are presented in Table I. All of the fits are very good as indicated by the small uncertainty in slope parameters, and the small value of the variance. The square root of the variance for a linear least-squares fit is a measure of the average deviation between data points and the fitted value. For all of the fits these average deviations are on the order of one to two times the experimental uncertainty of $\pm 7 \mathrm{~mm}$ for each point. Analysis of the actual differences between the data points and fitted values shows that most deviations are indeed less than $10 \mathrm{~mm}$, and few exceed $16 \mathrm{~mm}$, indicating that the motion is fairly smooth.

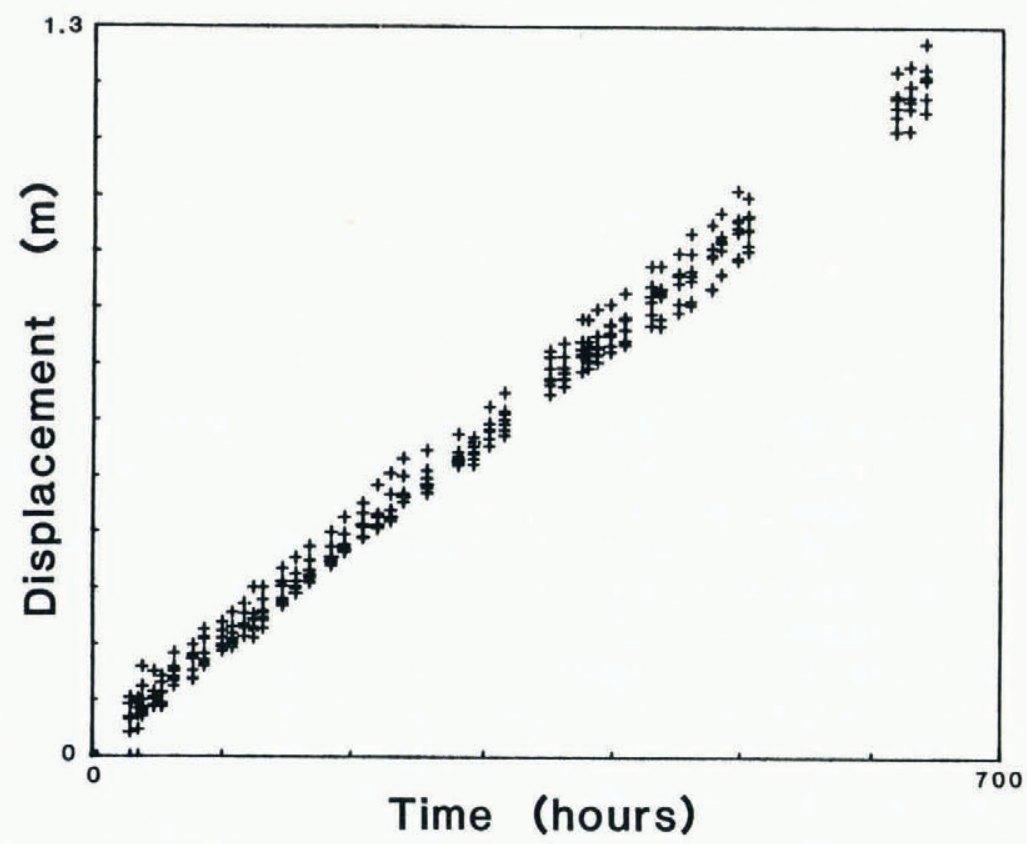

Fig. 2. 


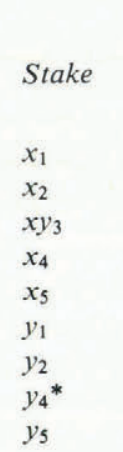

\section{TABLE I. FIT PARAMETERS}

\begin{tabular}{|c|c|}
\hline $\begin{array}{c}\text { Slope }(\text { Velocity }) \pm \sigma \\
\mathrm{m} / \mathrm{h}\end{array}$ & $\underset{\mathrm{m}}{(\text { Variance for } f i t)^{1 / 2}}$ \\
\hline $1.751 \pm 0.010 \times 10^{-3}$ & $12.0 \times 10^{-3}$ \\
\hline $1.884 \pm 0.008 \times 10^{-3}$ & $9.74 \times 10^{-3}$ \\
\hline $1.829 \pm 0.011 \times 10^{-3}$ & $12.7 \times 10^{-3}$ \\
\hline $1.873 \pm 0.007 \times 10^{-3}$ & $8.59 \times 10^{-3}$ \\
\hline $1.790 \pm 0.012 \times 10^{-3}$ & $14.1 \times 10^{-3}$ \\
\hline $1.902 \pm 0.014 \times 10^{-3}$ & $16.6 \times 10^{-3}$ \\
\hline $1.869 \pm 0.005 \times 10^{-3}$ & $9.01 \times 10^{-3}$ \\
\hline $1.751 \pm 0.033 \times 10^{-3}$ & $2.9 \times 10^{-3}$ \\
\hline $1.507 \pm 0.010 \times 10^{-3}$ & $13.3 \times 10^{-3}$ \\
\hline
\end{tabular}

*Determined from three points only.

\section{COHERENCE OF THE MOTION}

If the measured displacement for each stake truly represents the motion of the glacier, then for sufficiently small regions having the same overall average velocity, the short-term stake motions should be compatible. In effect, the displacements are all measurements of the same quantity and the data may be combined and tested for coherence. Since the stakes $y_{1}$ and $y_{5}$ showed significant variation from the others in their average velocity, they have not been included in the subsequent analysis. These extremes can be understood from a consideration of ice thickness, surface slope, and relation to bedrock topography in these locations. The rest of the analysis has been carried out using the elongated grid along the flow line shown below. The variation in average velocity for these remaining six stakes is less than $7 \%$.

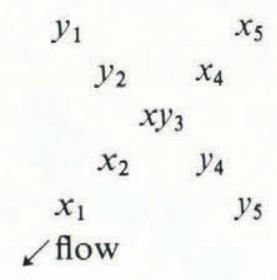

Using these six stakes, the average displacement for each of the 46 surveys was calculated, and this is shown plotted against time in Figure 3. The parameters for the linear least-squares fit to these data are: for the slope of the curve, $1.833 \pm 0.006 \times 10^{-3} \mathrm{~m} / \mathrm{h}$ as the average velocity of the array; variance $\left(6.70 \times 10^{-3} \mathrm{~m}\right)^{2}$. These indicate once again that a straight line is a very good fit to the data, i.e. the motion is very nearly uniform. Comparison of the measured with the fitted values shows that no differences exceed $13 \mathrm{~mm}$.

If the motion of the stakes is compatible, then deviations from the fits should occur simultaneously. To test for coherent structure in the data, individual deviations for the six stakes were summed for each of the 46 surveys and the average deviations were calculated along with their standard deviations. The greatest deviations are about $13 \mathrm{~mm}$, but in most cases the standard deviation is of the same order, indicating that the stake positions are not varying together. 


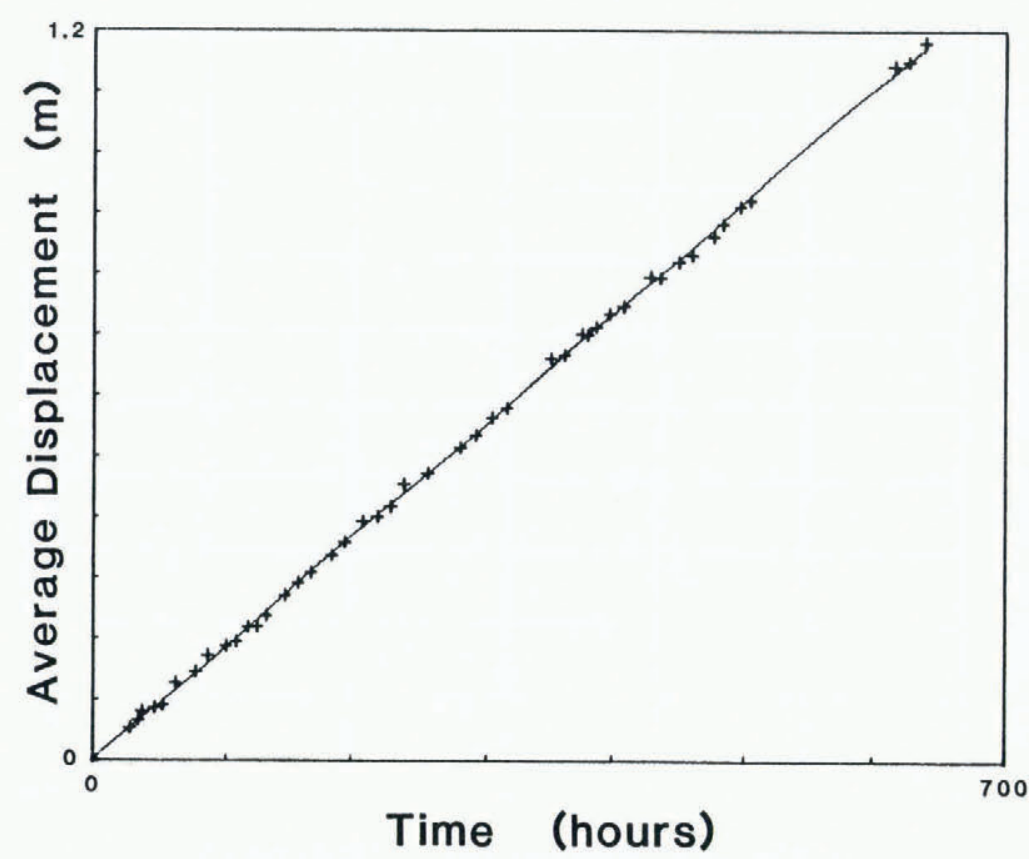

Fig. 3 .

\section{SHORT-TERM VELocities}

In order to study these results as variations over time rather than from fitted positions, velocities were computed from consecutive position measurements for each stake yielding an array of $46 \times 6$ velocities. For individual stakes, velocities showed typical standard deviations of $100 \%$ over time from their overall averages. The calculated experimental velocity resolution of $\pm 7 \mathrm{~mm} / 12 \mathrm{~h}$ is $30 \%$ of the overall average. This result is confirmed by Monte Carlo simulations of the resolution and is discussed below. The glacier moves too slowly, and the experimental uncertainty in position is too great to see accurately variations less than $30 \%$ over time periods this short. To increase the experimental resolution one must either look over longer time periods, measure the displacements more precisely, average more measurements, or study a faster glacier. Nevertheless, $30 \%$ is an acceptable resolution to study the coherence of effects of $100 \%$ which occur for individual stakes.

In order to test the coherence of these data, the individual $12 \mathrm{~h}$ velocities were averaged for the six stakes for each of the 46 surveys to determine the average $12 \mathrm{~h}$ velocities for the array and the standard deviation of these at each survey. By combining the data from the six stakes, time-dependent variation of these 46 average velocities was reduced from about $100 \%$, the value for single stakes, to $57 \%$. Significantly however, during any given $12 \mathrm{~h}$ period the variations among individual element velocities were larger. Typically the standard deviation for the average velocities of the six elements at any given time was $65 \%$. Thus the individual stake velocities, although varying typically $100 \%$, are not on the average varying together.

Figure 4 is a plot of the $12 \mathrm{~h}$ deviations for average velocity of all six stakes expressed as a percent of the overall average velocity $(1.83 \mathrm{~mm} / \mathrm{h})$, versus the standard deviation of this value, 


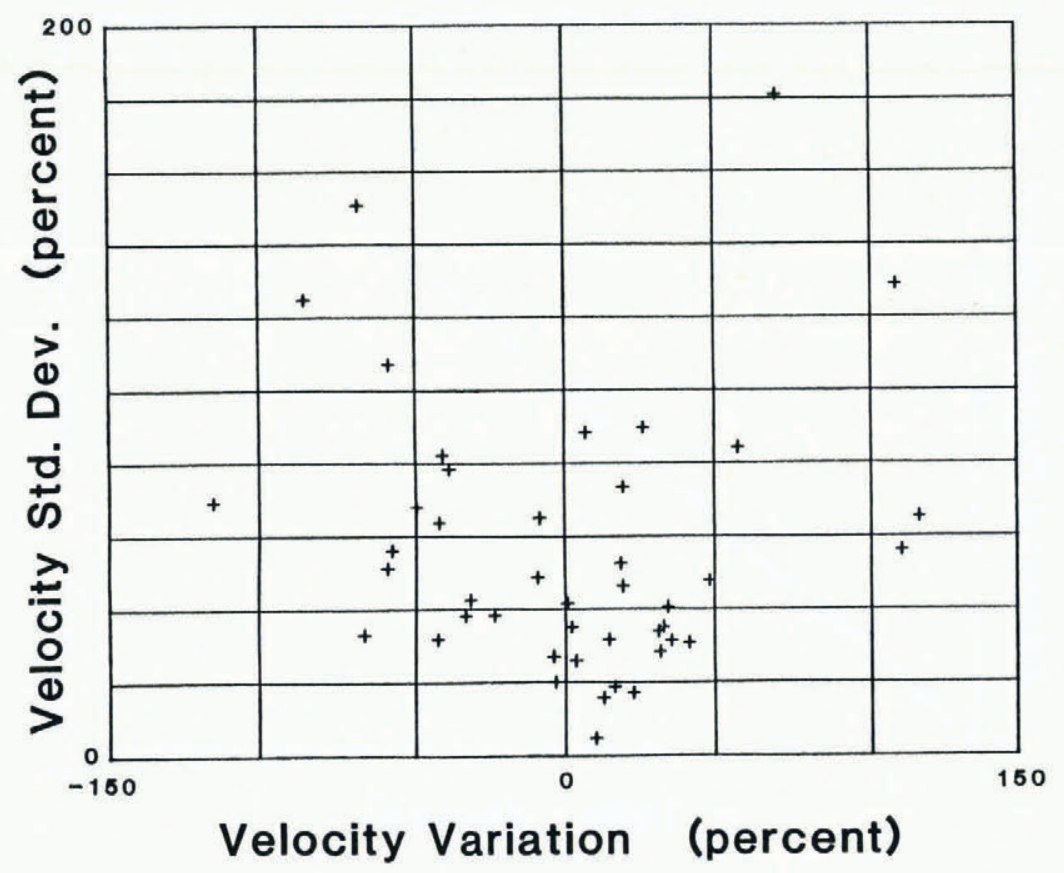

Fig. 4.

also expressed as a percent of overall average velocity. Non-uniform compatible motion during any $12 \mathrm{~h}$ period will be indicated by large deviations with small uncertainties (in the lower corners of such a plot). Examination of the plot shows that occasionally a large variation will appear, but always it occurs with a high value of standard deviation. Significantly, it is generally true that all velocities near the overall average (center of the plot) are in much better agreement (low ordinate value) than those farther away from the average.

In order to look for structure in the data with slightly longer time duration, which should be seen with better resolution, the analysis program was modified to fit displacements three points $(36 \mathrm{~h})$ at a time, and to plot slopes (velocities) for all adjacent three-point combinations over the entire range. This process was then repeated for longer time combinations of adjacent points. The general trend in all these plots is that the percentage deviations in velocity from the overall average decrease as more points are included, and the fluctuations approach the calculated resolution.

\section{RESOLUTION STUDIES}

The analysis presented thus far indicates that short-term variations in the motion are not in phase, and therefore that they represent either highly localized variation in ice velocity, or effects due to measurement uncertainty.

In order to test the latter hypothesis, Monte Carlo simulations of the data were made to check the experimental resolution. A data array was computer-generated with displacements randomly distributed about the fitted value for each stake at each survey. These random 
TABLE II. RESOLUTION STUDIES BASED ON 12 h VELOCITY VARIATIONS (STANDARD DEVIATI INS)

\begin{tabular}{|c|c|c|c|c|}
\hline & Resolution & $\begin{array}{l}\text { Variation } \\
\text { over time } \\
\text { (typical for } \\
\text { any one stake) }\end{array}$ & $\begin{array}{l}\text { Variation } \\
\text { over time } \\
\text { (six stake } \\
\text { average) }\end{array}$ & $\begin{array}{c}\text { Variation } \\
\text { among six } \\
\text { stakes } \\
\text { (fixed time) }\end{array}$ \\
\hline Data & $\pm 5 \mathrm{~mm}$ & $100 \%$ & $57 \%$ & $64 \%$ \\
\hline Monte Carlo & gaussian & & & \\
\hline simulation & $\sigma= \pm 5 \mathrm{~mm}$ & $33 \%$ & $13 \%$ & $27 \%$ \\
\hline Monte Carlo & gaussian & & & \\
\hline simulation & $\sigma= \pm 16 \mathrm{~mm}$ & $100 \%$ & $40 \%$ & $90 \%$ \\
\hline
\end{tabular}

displacements were weighted according to a gaussian distribution using a standard deviation equal to $\pm 0.005 \mathrm{~m}$, the uncertainty of the actual measurements. This data array was then run through the analysis program and velocity deviations were calculated. These results are summarized in Table II and show velocities that vary in time by about $30 \%$ for each stake, and that this variation is reduced to $13 \%$ when data for all six stakes are combined. This reduction to $13 \%$ is very nearly equal to $\sqrt{6} / 6 \times 30 \%$, the factor which is expected from combining randomly distributed data from six stakes.

This indicates that the observed variations in velocity of $100 \%$ for individual stakes are only partly due to measurement uncertainties. They must therefore represent to some degree uncorrelated motion of regions on the ice surface separated by 50 to $200 \mathrm{~m}$.

Further Monte Carlo studies were run in order to simulate truly random deviations as large as $100 \%$ for individual stakes in order to compare these to the experimental data. Random fluctuations of $100 \%$ correspond to an experimental resolution of about $\pm 0.016 \mathrm{~m}$ and do not behave like the experimental data. As expected, the randomly produced variations are reduced by $\sqrt{6} / 6$ to $40 \%$ when all stakes are combined, whereas the experimental data are reduced to only $57 \%$. Further, the variations among stakes at a given time are about $90 \%$, whereas the experimental data show somewhat more agreement with only a $64 \%$ variation. These results show that the experimental data display a slightly more systematic variation than can be expected from purely randomly distributed displacements, although the motion is still far from coherent. Perhaps the systematic component represents a small part of the motion which is in fact coherent, or has been systematically induced in the corrections for atmospheric effects applied to all stakes at each survey.

\section{Conclusion}

The results presented here show that the surveyed area of South Cascade Glacier is moving at an average velocity of $1.83 \times 10^{-3} \mathrm{~m} / \mathrm{h}$, and that the variations in average velocity over periods of $12 \mathrm{~h}$ of a grid of six stakes equal in extent to the ice thickness are typically $57 \%$ (one standard deviation). These velocity variations in time are of the same order as the variations at fixed time between individual elements of the grid and thus do not indicate compatible motion for the array. Monte Carlo simulations of the experimental resolution show that only $30 \%$ of the variation can be attributed to measurement uncertainty, and that therefore the observed effects represent real, but localized variations in surface velocity. One possible mechanism which may account for these results is suggested by the work of Meier and others (1957) who have studied the opening rates of crevasses and found surface motion in these areas to be quite jerky. The 
studied area of South Cascade Glacier contained several transverse crevasses which had begun to appear during the time data were being taken. In any case, it is highly unlikely that the measured irregularities in the motion on the surface of this glacier are due to basal slip.

The method utilized in this experiment demonstrates an effective technique for determining compatible motion on a glacier surface. It would be very useful to see similar results from a glacier with a greater surface velocity.

\section{ACKNOWLEDGEMENT}

Grateful acknowledgement is given to the U.S. Geological Survey Project Office Glaciology for their generous loan of equipment and use of facilities on South Cascade Glacier.

MS. received 23 March 1981

\section{REFERENCES}

Engelhardt, H. F. and others. 1978. Basal sliding and conditions at the glacier bed as revealed by bore-hole photography, by H. F. Engelhardt, W. D. Harrison, and [W.] B. Kamb. Journal of Glaciology, Vol. 20, No. 84, p. 469-508.

Harrison, A. E., and Lee, D. 1971. Electronic measurement of ice velocity. Journal of Glaciology, Vol. 10, No. 60, p. 394-99.

Meier, M. F. 1960. Mode of flow of Saskatchewan Glacier, Alberta, Canada. U.S. Geological Survey. Professional Paper 351.

Meier, M. F., and others. 1957. Preliminary study of crevasse formation, by M. F. Meier [and 5 others]. U.S. Snow, Ice and Permafrost Research Establishment. Report 38.

Paterson, W. S. B. 1969. The physics of glaciers. Oxford, etc., Pergamon Press. (The Commonwealth and International Library. Geophysics Division.) 